\title{
Substituição de lâmpadas fluorescentes por light emitting diode (LED) em uma instituição de ensino: preocupação ambiental, energética e econômica
}

\author{
Replacement of fluorescent lamps with light emitting diode (LED) in an \\ educational institution: environmental, energetic and economic concern
}

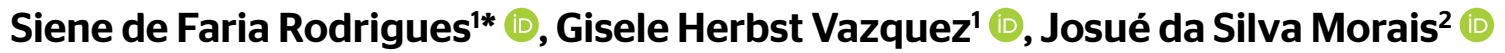

\begin{abstract}
RESUMO
As lâmpadas fluorescentes (LFs) podem causar sérios problemas ambientais e à saúde humana. Tal fato se deve à presença de mercúrio em sua constituição e, quando descartadas inadequadamente, podem ocasionar a contaminação do solo, do ar e da água. Já as lâmpadas light emitting diode (LED), além de mais econômicas e com maior vida útil que as fluorescentes, proporcionam maior luminosidade e, ao serem substituídas, não contaminam o meio ambiente. O objetivo deste estudo foi avaliar a substituição das LFs pelas lâmpadas LED na Universidade Federal de Uberlândia (UFU), em Uberlândia, Minas Gerais, analisando seu impacto ambiental e a viabilidade econômica e financeira. Concluiu-se que as lâmpadas LED se sobressaem nos aspectos de manutenibilidade, durabilidade, eficiência energética, economia e menores impactos ambientais, podendo ser até duas vezes mais eficientes que as LFs, além de não gerarem resíduos tóxicos. Diante desse cenário, constatou-se a viabilidade econômico-financeira para a substituição das LFs por LED na UFU, pois, considerando-se uma amostra de 1.000 LFs, projetou-se uma economia entre 55,75 e 80,78\% ao completar 13 anos e um retorno do montante gasto ao final do primeiro ano. Não obstante, o que mais se destacou nessa experiência foi a importância da substituição do ponto de vista ambiental, por contemplar ações de sustentabilidade, principalmente em uma instituição de ensino.
\end{abstract}

Palavras-chave: resíduos sólidos; mercúrio; light emitting diode.

\begin{abstract}
Fluorescent lamps (FLS) can cause serious environmental and human health problems. This is due to the presence of mercury in its constitution and that, when discarded improperly, they can cause soil, air and water contamination. Light emitting diode (LED) lamps, in addition to being more economic and with a life longer than fluorescent lamps', they provide greater brightness and, when replaced, do not contaminate the environment. The objective of this study was to evaluate the substitution of FLs with LED at the Federal University of Uberlândia (UFU), in Uberlândia, Minas Gerais (Brazil), by analyzing their environmental impact and economic and financial viability. It was possible to conclude that LED lamps stand out in terms of maintainability, durability, energy efficiency, economy and lower environmental impacts, being up to twice as efficient as FLs and not generating toxic waste. In this scenario, the economic and financial viability for FL's substitution in UFU was verified, since that if a sample of 1,000 FLs was considered, the projected economy was between 55.75 and $80.78 \%$ by the end of 13 years and the return of the amount spent at the end of the first year. However, what stood out most in this experiment was the importance of the replacement from the environmental point of view, since it primarily contemplates sustainability actions in an educational institution.
\end{abstract}

Keywords: solid waste; mercury; light emitting diode.

\section{INTRODUÇÃO}

A gestão ambiental e a eficiência energética são assuntos preponderantes na atualidade, pois ambas buscam a utilização racional dos recursos, visando à sustentabilidade. A eficiência energética consiste em obter o melhor desempenho na produção de um serviço com o menor gasto de energia,

como, por exemplo, a modernização de equipamentos e processos no sentido de reduzir seu consumo, o que também contribui para a economia.

Após a crise energética de 2001 no Brasil, a necessidade de redução de consumo de energia elétrica para evitar o racionamento impulsionou diversas ações e projetos vislumbrando a melhoria da eficiência 
no consumo de energia. Nesse momento, as lâmpadas incandescentes (LIs), utilizadas de forma majoritária na iluminação artificial, passaram a ser substituídas pelas de descarga, entre elas, as fluorescentes, mais eficientes e econômicas, mas que, devido à presença de mercúrio em sua constituição, enquadram-se como resíduos sólidos perigosos, devendo ser tratadas de forma diferente na etapa de pós-consumo.

Pela sua composição química, as lâmpadas fluorescentes (LFs) resultam em resíduos sólidos perigosos que causam danos ao meio ambiente e às pessoas, necessitando de descarte adequado. Por serem utilizadas em grande escala pela sociedade, seu descarte também tem sido volumoso e feito de forma indiscriminada, podendo ser encontradas em terrenos baldios, vales, lixões e aterros sanitários e algumas armazenadas em depósitos abertos, sujeitos a invasões e utilização indevida. Quando descartadas em locais inadequados, podem contaminar o meio ambiente e intoxicar os seres humanos causando problemas físicos e neurológicos (CESTARI; MARTINS, 2015).

Apesar de considerado pela Política Nacional de Resíduos Sólidos (PNRS) (BRASIL, 2010), o gerenciamento das lâmpadas ainda é recente no Brasil. Em algumas instituições públicas já existem projetos básicos para a destinação e o manuseio pós-consumo, definindo-se as necessidades imediatas e os pontos críticos de intervenção que, independentemente do investimento, visam à minimização de riscos de exposição e contaminação dos trabalhadores e do meio ambiente pelo mercúrio (COMINI et al., 2016).

Por sua vez, desde 2001, o Brasil tem um importante instrumento para implantação da eficiência energética, a Lei no 10.295 (Lei de Eficiência Energética), que estimula o desenvolvimento tecnológico, a preservação ambiental e a introdução de produtos mais eficientes no mercado nacional (BRASIL, 2001). Por exigência dessa lei, a partir de 2017, LIs acima de $25 \mathrm{~W}$ não podem mais ser comercializadas, sendo aplicadas multas, cujo valor varia de R\$ 100 a R \$ 1,5 milhão pelo seu descumprimento (ABDALLA, 2017).

Assim, levando-se em consideração os problemas ambientais do uso das LFs e a baixa eficiência energética das LIs e a sua retirada do mercado, as lâmpadas light emitting diode (LED), por apresentarem vida útil e eficiência energética melhores que as de descarga atuais, passaram a ser largamente utilizadas. Segundo Santos et al. (2015), a lâmpada LED tem um componente eletrônico semicondutor, com a mesma tecnologia utilizada nos chips de computadores. Esses componentes têm a propriedade de transformar energia elétrica em luz, não utilizando de filamentos metálicos, radiação ultravioleta, nem descarga de gases. É um componente bipolar com dois terminais (chamados cátodo e ânodo) que, quando polarizados, permitem a passagem de corrente elétrica, gerando luz.

O objetivo deste estudo foi avaliar a substituição das LFs pelas lâmpadas LED na Universidade Federal de Uberlândia (UFU), em Uberlândia, Minas Gerais, analisando seu impacto ambiental e a viabilidade econômica e financeira.

\section{REFERENCIAL TEÓRICO}

\section{Política Nacional de Resíduos Sólidos e a responsabilidade pós-consumo}

Atualmente, com o crescimento urbano desordenado das cidades brasileiras, o lixo produzido tem sido uma grande preocupação, principalmente quanto ao descarte de resíduos sólidos, como lâmpadas, pilhas e baterias (AGUILAR, 2015).

Segundo a NBR 10004/2004, da Associação Brasileira de Normas Técnicas (ABNT, 2004), um resíduo é considerado perigoso quando:

- suas propriedades físicas, químicas e infectocontagiosas representam risco para a saúde pública e para o meio ambiente;

- apresentam ao menos um dos cinco critérios de periculosidade: inflamabilidade, corrosividade, reatividade, toxicidade e patogenicidade.

Na tentativa de minorar os impactos ao meio ambiente e à saúde dos seres vivos, a PNRS reúne um conjunto de princípios, objetivos, instrumentos, diretrizes, metas e ações adotadas pelo governo federal, isoladamente ou em regime de cooperação com os Estados e municípios (BRASIL, 2010). Visa à gestão integrada e ao gerenciamento ambientalmente adequado dos resíduos sólidos conforme dispõe seu art. $4^{\circ}$, o qual prioriza a articulação entre as diferentes esferas do poder público, $\mathrm{e}$ destas com o setor empresarial, aspirando à cooperação técnica e financeira (CONSELHO REGIONAL DE QUÍMICA - IV REGIÃO, 2015).

A PNRS pretende tornar o Brasil um modelo na gestão de resíduos sólidos, estabelecendo a responsabilidade compartilhada pela destinação final e ecologicamente correta de produtos no pós-consumo. Assim, fabricantes, importadores, distribuidores, comerciantes, consumidores e poder público são igualmente responsáveis pelo destino correto dos resíduos, que devem ser reaproveitados, reciclados ou, apenas no caso de rejeitos, encaminhados para aterros sanitários (BRASIL, 2010). A PNRS estabelece também que seja elaborado um planejamento com o intuito de reduzir os impactos durante a produção das lâmpadas e os resíduos sejam recolhidos pelo fabricante, que utilizará a logística reversa com o intuito de reaproveitar a matéria-prima das lâmpadas descartadas (MAIA et al., 2014).

\section{Lâmpadas fluorescentes e seus impactos}

As LFs tubulares são lâmpadas de descarga de baixa pressão. Elas consistem de um tubo de vidro revestido internamente com pó de fósforo e têm eletrodos de fios de tungstênio. $\mathrm{O}$ tubo é preenchido com gases inertes e um não inerte, como o mercúrio (Hg). A luz ultravioleta (UV) é emitida pela passagem de corrente elétrica entre os eletrodos, criando um arco de baixa intensidade que excita o vapor de mercúrio e produz radiação, a qual excita os átomos de fósforo, ocorrendo a emissão de luz visível. Para funcionarem, precisam de reatores, que são equipamentos auxiliares que limitam a corrente e ajustam as tensões para o perfeito funcionamento da lâmpada (CESTARI; MARTINS, 2015). 
Segundo Crepaldi, Frigatti e Luckow (2012), as LFs têm característica de resistência negativa, ou seja, uma particularidade volt-ampère negativa. Isso significa que a corrente elétrica aumenta tanto a ponto de destruir a lâmpada em pouco tempo, o que justifica a existência do reator, que atua limitando o aumento da corrente elétrica. No momento da partida da LF, a tensão inicial pode chegar a valores elevados, até cerca de $1.200 \mathrm{~V}$, sendo função do reator diminuí-la no momento da ignição. Pode-se dizer, no entanto, que essas características de sobretensão e temperatura inadequada de ignição das LF são a causa de um excessivo e precoce desgaste dos filamentos, o que faz com que a lâmpada seja danificada com pouco tempo de uso.

Sendo as LFs um resíduo perigoso classe I devido ao mercúrio, a PNRS tem servido de parâmetro para futuras mudanças no processo de gerenciamento de lâmpadas dentro das instituições, pois se tem consciência de que a presença desse elemento no corpo humano pode ocasionar grandes danos à saúde, lesionando principalmente os rins, o fígado, o aparelho digestivo e o sistema nervoso central (ESTRELA; ROHLFS, 2014).

O mercúrio tem elevada capacidade de dispersão e se volatiliza facilmente em temperatura ambiente, persistindo nos ambientes na forma de metilmercúrio após transformação por meio de metabolismo microbiano. O metilmercúrio tem a capacidade de acumular-se nos organismos e concentrar-se nas cadeias alimentares, principalmente a aquática, contaminando os peixes e tornando-os a principal via de exposição e contaminação (GUSMÃO, 2017). A ingestão desses alimentos contamina o ser humano, causando o aparecimento de diversos sintomas. Estes manifestam-se, sobretudo, nas células do sistema nervoso, originando sintomas neurológicos, como microcefalia, hipoplasia e atrofia do cérebro, podendo aparecer, também, tremores nas mãos e eretismo (comportamento anormal e introvertido), gengivite, insônia, vômitos, dores de cabeça, elevação da pressão arterial, lesões renais, danos e convulsões (CESTARI; MARTINS, 2015).

Não existe legislação brasileira que estabeleça limites de concentração de mercúrio nas lâmpadas, e as empresas fabricantes do material, em sua maioria, tornaram-se praticamente importadoras. A logística reversa facilita a separação dos materiais e proporciona maior índice de reciclagem no país, reduzindo, com isso, o volume de resíduos descartados e a pressão sobre o meio ambiente (GUSMÃO, 2017).

\section{Logística reversa}

A implementação da logística reversa, principal instrumento da PNRS, visa garantir o aumento do porcentual de reciclagem no Brasil - atualmente baixo, de $13 \%$ de resíduos secos, e que poderia ser próximo de 30\% (GUSMÃO, 2017).

A logística reversa engloba coletar, transportar e processar materiais que foram descartados para assegurar uma recuperação sustentável, sendo que esses materiais processados podem ser utilizados para os mais diversos fins (SHIBÃO; MOORI; SANTOS, 2010), o que pode significar uma economia anual aos cofres da União da ordem de R\$ 8 bilhões, além de evitar que esses resíduos cheguem aos aterros sanitários (GUSMÃO, 2017).

Os benefícios da logística reversa são muitos, porém os mais importantes se resumem a demandas ambientais com normas que levam as empresas a se preocuparem com a destinação final de produtos e embalagens por elas produzidos e que, normalmente, são descartados de forma incorreta pelo consumidor. A eficiência econômica também é de suma importância, pois permite a geração de ganhos financeiros pela economia no uso de recursos e reciclagem para reaproveitamento do material e ganho de imagem e status perante os sindicatos, a população e até mesmo órgãos públicos que incentivam a responsabilidade social com o meio ambiente e com a saúde do ser humano (BACILA, 2012).

Em 5 de julho de 2012, o Ministério do Meio Ambiente (MMA) publicou um edital de chamamento convocando o setor para apresentação de uma proposta de Acordo Setorial para implantação da logística reversa em todo o país. Assim, em, 27 de novembro de 2014, surgiu o Programa Reciclus, entidade sem fins lucrativos que deveria implementar, em cinco anos (sendo 2017 o ano I), o Sistema de Logística Reversa de Lâmpadas Fluorescentes de Vapor de Sódio e Mercúrio e de Luz Mista pela União, por intermédio do MMA, a Associação Brasileira da Indústria da Iluminação (ABILUX), a Associação Brasileira de Importadores de Produtos de Iluminação (ABILUMI) e empresas fabricantes, importadoras, comerciantes e distribuidoras de lâmpadas (RECICLUS, 2017). As empresas que aderirem ao sistema de logística reversa deverão disponibilizar o espaço para alocação de um coletor, e o custo para o processo ficará a cargo das empresas importadoras e fabricantes, que serão obrigadas a pagar $\mathrm{R} \$ 0,40$ para a entidade gestora (Reciclus) por unidade fabricada ou importada, sendo a meta, em 2019, de reciclar 20\% do total das lâmpadas importadas e produzidas no Brasil em 2012 (aproximadamente 300 milhões) (DEGRA; GOBI, 2015).

\section{Lâmpadas light emitting diode (LED)}

LED é a sigla de light emitting diode (em português, significa diodo emissor de luz). São componentes eletrônicos que emitem luz através de eletroluminescência, transformando energia elétrica em radiação visível. O LED existe desde 1962 e era utilizado apenas para sinalização devido ao seu baixo fluxo luminoso, restrita gama de cores e baixa potência. Em meados da década de 1990, surgiu o LED azul com alto fluxo luminoso que, com uma camada de fósforo, gera luz branca, possibilitando, com isso, a utilização do LED na iluminação (BLEY, 2012). No Brasil, não há regulamentações específicas para o descarte de lâmpadas LED nem classificação desse tipo de lâmpadas na PNRS.

Essa lâmpada é composta por um bulbo de LED disposto em um dissipador de calor (pois a quantidade de luz emitida pelo LED diminui com o aumento da temperatura, por isso tem a necessidade desse 
dispositivo) e de um driver. Os LEDs podem ser classificados em três categorias: indicativos, de alto brilho e de potência. O LED emite luz monocromática e o comprimento de onda está relacionado ao tipo de material utilizando na composição do semicondutor. A dopagem do cristal pode ser feita com gálio, alumínio, arsênio, fósforo, índio e nitrogênio. Essa variedade de elementos químicos e a sua combinação permitem a emissão de luz em uma ampla faixa do espectro (LIMA, 2013).

\section{METODOLOGIA}

O estudo foi realizado na UFU, localizada em Uberlândia, no período de novembro de 2016 a setembro de 2017. A UFU tem cerca de 22.453 alunos distribuídos em sete campi universitários, ou seja, a sede Uberlândia com quatro campi (Educação Física, Glória, Santa Mônica e Umuarama) e três localizados nas cidades de Ituiutaba, Monte Carmelo e Patos de Minas. A instituição oferece 75 cursos de graduação, 20 de doutorado, 39 de mestrado acadêmico, seis de mestrado profissional e diversos cursos de especialização lato sensu, além de cursos técnicos da área de saúde e meio ambiente realizados pela Escola Técnica de Saúde (ESTES) e ensino a distância (seis de graduação, cinco de especialização, 11 de extensão e oito de aperfeiçoamento). A UFU tem, também, uma escola de ensino básico, a Escola de Educação Básica (ESEBA).

Assim, três etapas foram realizadas: requisição de documentos oficiais e visitas aos locais de armazenamento das lâmpadas queimadas para avaliação; extração de dados dos documentos fornecidos pela instituição para quantificação; e qualificação das lâmpadas descartadas e estudo da viabilidade econômica da substituição das LFs por lâmpadas LED dentro da UFU.

Nas instituições públicas, todo o processo de aquisição de material e contratação de serviços necessita de submissão a processos licitatórios. Na UFU, as lâmpadas queimadas ficam armazenadas por períodos variáveis de 6 a 18 meses aguardando a confecção de um Projeto Básico que determine a quantidade de lâmpadas inteiras e quebradas a serem recolhidas e receber a destinação adequada, assim como o valor médio a ser pago por esse serviço. Com essas informações, a Divisão de Licitação elabora um pregão eletrônico, em que as empresas apresentam suas propostas, vencendo a de menor preço.

Antes de 2014, as lâmpadas queimadas eram descartadas em lixo comum. Como a UFU é uma instituição de ensino que se preocupa com a preservação do meio ambiente e, ainda, para atender à Lei $n^{\circ}$ 12.305/2010 (BRASIL, 2010), referente à gestão de resíduos sólidos, instituiu processos para o descarte adequado desse material.

Assim, neste estudo, foram analisados dois editais de licitação e um projeto básico: o Pregão Eletrônico nº 061, de 2014 (UFU, 2014), o Pregão Eletrônico n 076, de janeiro a setembro de 2015 (UFU, 2015), e o Projeto Básico, de outubro de 2015 a julho de 2017 (UFU, 2017), uma vez que o pregão eletrônico não havia sido finalizado. Com base nesses documentos, foi possível realizar levantamentos qualiquantitativos das lâmpadas descartadas e os seus custos. Nos meses de março e junho de 2017, foram realizadas visitas aos locais de armazenamento para conhecimento da forma atualmente empregada para a estocagem das lâmpadas queimadas.

Para demonstrar a viabilidade econômica e as relações de custo-benefício da substituição das LFs pelas LED, cálculos foram realizados a partir de uma amostra de mil lâmpadas, tomando-se como base 26 salas de aula do bloco 5R localizado no Campus Santa Mônica, em Uberlândia. Esse bloco foi o escolhido por representar, em similaridade, as demais unidades de salas de aulas dos campis da UFU, além de contemplar os critérios de adoção das normas técnicas brasileiras de instalações elétricas.

\section{RESULTADOS E DISCUSSÃO}

\section{Gerenciamento de resíduos sólidos e o local de armazenamento das lâmpadas}

Enquanto cada processo de licitação tramita, as lâmpadas que contêm mercúrio metálico, dos tipos fluorescentes e de vapor de sódio, de vapor metálico, mistas, halógenas e outros tipos de uso técnico especializado inservíveis de todos os campis, ficam depositadas em um galpão alugado na cidade de Uberlândia, Minas Gerais fora do campi, adaptado às cláusulas do contrato de locação para atender às condições de segurança ambiental.

O Projeto Básico estabelece normas gerais e específicas, métodos de trabalho e padrões de conduta para os serviços de manuseio, transporte e descarte, com o objetivo de evitar rompimentos e a liberação de produtos tóxicos para a destinação final das lâmpadas.

Assim, de acordo com o Projeto Básico, além de acondicionar as lâmpadas em vasilhames apropriados indevassáveis, que garantam o transporte com segurança, a empresa vencedora deverá fazer a descontaminação do material e a reciclagem dos resíduos aproveitáveis. O descarte dos resíduos não aproveitáveis deverá ser feito em local aprovado pelo órgão ambiental competente. Nenhuma etapa desse processo de descarte e reciclagem poderá ser realizada nas dependências da UFU, independentemente do processo utilizado, com exceção apenas da etapa de coleta em data previamente marcada.

Na UFU, porém, detectou-se que o local de armazenamento de lâmpadas pós-consumo está em seu limite máximo, havendo ainda lâmpadas quebradas, necessitando de providências imediatas com o intuito de se preservar a segurança de seus colaboradores e do meio ambiente. Segundo Naime e Garcia (2004), uma LF, enquanto estiver intacta, não oferece nenhum risco ambiental aos meios físico, biológico e antrópico, porém, ao ser rompida, o mercúrio existente em seu interior se libera sob a forma de vapor podendo ser inalado por quem manuseia o resíduo. As lâmpadas quebradas acidentalmente deverão 
ser separadas das demais e guardadas em recipientes herméticos, como tambores de aço com vedação adequada (SANCHES, 2008). Também não se devem embutir os pinos de contato elétrico para identificar as LFs inservíveis, prática condenada, já que os orifícios resultantes nos soquetes das extremidades da lâmpada permitem o vazamento do mercúrio para o ambiente (LIMA, 2007).

\section{Quantidade estimada de lâmpadas para descarte e orçamento}

Em 2014, a quantidade descartada de lâmpadas inteiras foi de 30.120 unidades e a de lâmpadas quebradas de $30 \mathrm{~kg}$, sendo contabilizados apenas os campi Umuarama e Santa Mônica (Tabela 1).
De janeiro a setembro de 2015, foram retiradas 38 mil lâmpadas inteiras e $850 \mathrm{~kg}$ de lâmpadas quebradas, sendo contabilizados seis campi e o Hospital das Clínicas (Tabela 2).

No ano de 2016, não houve recolhimento de lâmpadas queimadas na UFU, sendo o levantamento realizado em julho de 2017. Assim, de outubro de 2015 a julho de 2017, o número de lâmpadas descartadas mais que dobrou em relação ao período de janeiro a setembro de 2015, ou seja, 78 mil unidades nos mesmos campi descritos anteriormente (Tabela 3).

Outras instituições de ensino superior também procuram descartar corretamente suas LFs, como a Universidade Federal de Viçosa (UFV), que, de 2011 a 2014, descartou 60 mil lâmpadas de descarga inteiras em empresas licenciadas (COMINI et al., 2016), e a Universidade de São

Tabela 1 - Lâmpadas descartadas em 2014 nas unidades da Universidade Federal de Uberlândia (UFU), Minas Gerais.

\begin{tabular}{|c|c|c|c|c|c|c|}
\hline \multirow[b]{2}{*}{ Local de retirada } & \multicolumn{5}{|c|}{ Lâmpadas inteiras (unidades) } & \multirow{2}{*}{$\begin{array}{l}\text { Lâmpadas } \\
\text { quebradas (kg) }\end{array}$} \\
\hline & $\begin{array}{c}\text { Fluorescentes } \\
\text { tubulares }\end{array}$ & $\begin{array}{l}\text { Vapor } \\
\text { de sódio }\end{array}$ & $\begin{array}{l}\text { Vapor de } \\
\text { mercúrio }\end{array}$ & $\begin{array}{c}\text { Vapor } \\
\text { metálico }\end{array}$ & $\begin{array}{l}\text { Lâmpadas } \\
\text { compactas }\end{array}$ & \\
\hline Campus Umuarama & 10.000 & 20 & - & - & 20 & 10 \\
\hline Campus Santa Mônica & 20.000 & 30 & 05 & 15 & 30 & 20 \\
\hline Total de lâmpadas & 30.000 & 50 & 05 & 15 & 50 & 30 \\
\hline
\end{tabular}

Fonte: com base em UFU (2014).

Tabela 2 - Lâmpadas descartadas em 2015 nas unidades da Universidade Federal de Uberlândia (UFU), Minas Gerais.

\begin{tabular}{|c|c|c|c|c|c|}
\hline \multirow[b]{2}{*}{ Local de retirada } & \multicolumn{4}{|c|}{ Lâmpadas Inteiras (unidades) } & \multirow{2}{*}{$\begin{array}{l}\text { Lâmpadas } \\
\text { quebradas (kg) }\end{array}$} \\
\hline & $\begin{array}{c}\text { Fluorescentes } \\
\text { tubulares }\end{array}$ & $\begin{array}{l}\text { Vapor } \\
\text { de sódio }\end{array}$ & $\begin{array}{c}\text { Compactas e } \\
\text { incandescentes }\end{array}$ & $\begin{array}{l}\text { Vapor } \\
\text { metálico }\end{array}$ & \\
\hline Hospital das Clínicas & 3.000 & - & - & - & 125 \\
\hline Campus Umuarama & 15.000 & 100 & 100 & 50 & 250 \\
\hline Campus Santa Mônica & 15.000 & 100 & 100 & 50 & 250 \\
\hline Campus Educação Física & 1.000 & - & 100 & - & 25 \\
\hline Campus Patos de Minas & 800 & - & 100 & - & 100 \\
\hline Campus Monte Carmelo & 1.000 & - & - & - & 50 \\
\hline Campus Ituiutaba & 1.500 & - & - & - & 50 \\
\hline Total de lâmpadas & 37.300 & 200 & 400 & 100 & 850 \\
\hline
\end{tabular}

Fonte: com base em UFU (2015).

Tabela 3 - Lâmpadas descartadas de outubro de 2015 a julho de 2017 nas unidades da Universidade Federal de Uberlândia (UFU), Minas Gerais.

\begin{tabular}{|c|c|c|c|c|c|}
\hline \multirow[b]{2}{*}{ Local de retirada } & \multicolumn{4}{|c|}{ Lâmpadas inteiras (unidades) } & \multirow{2}{*}{$\begin{array}{l}\text { Lâmpadas } \\
\text { quebradas (kg) }\end{array}$} \\
\hline & $\begin{array}{c}\text { Fluorescentes } \\
\text { tubulares }\end{array}$ & $\begin{array}{c}\text { Vapor } \\
\text { de sódio }\end{array}$ & $\begin{array}{c}\text { Compactas e } \\
\text { incandescentes }\end{array}$ & $\begin{array}{l}\text { Vapor } \\
\text { metálico }\end{array}$ & \\
\hline Hospital das Clínicas & 3.000 & - & - & - & 125 \\
\hline Campus Umuarama & 35.000 & 100 & 100 & 50 & 250 \\
\hline Campus Santa Mônica & 35.000 & 100 & 100 & 50 & 250 \\
\hline Campus Educação Física & 1.000 & - & 100 & - & 25 \\
\hline Campus Patos de Minas & 800 & - & 100 & - & 100 \\
\hline Campus Monte Carmelo & 1.000 & - & - & - & 50 \\
\hline Campus Ituiutaba & 1.500 & - & - & - & 50 \\
\hline Total de lâmpadas & 77.300 & 200 & 400 & 100 & 850 \\
\hline
\end{tabular}

Fonte: com base em UFU (2017). 
Paulo (USP, capital), que, entre 2015 e 2017, encaminhou 106.343 LFs inteiras e $332,6 \mathrm{~kg}$ de LFs quebradas para tratamento, o que resultou em $14.221 \mathrm{~kg}$ de vidro, $830 \mathrm{~kg}$ de metal e $296 \mathrm{~g}$ de mercúrio reciclados (USP PREFEITURA, 2017).

Embora o número de lâmpadas tenha dobrado na UFU, o valor mensal, porém, diminuiu, visto que o descarte, em 2015, abrangeu 9 meses, totalizando 4.222 lâmpadas.mês ${ }^{-1}$ e, de outubro de 2015 a julho de 2017, foram 22 meses, com 3.545 lâmpadas.mês ${ }^{-1}$, o que pode ser justificado pela substituição parcial das lâmpadas em virtude da crise econômica

Nos anos avaliados, a quantidade de LF foi bem superior aos demais tipos de lâmpadas (vapor de sódio, vapor de mercúrio, vapor metálico, compactas e incandescentes), representando entre 98,1 e 93,9\% de todas as lâmpadas descartadas na instituição, o que indica o quanto é importante um gerenciamento correto e adequado desse resíduo tóxico.

De 2014 a julho de 2017, a UFU descartou 144.600 LFs tubulares inteiras. Sabe-se que cada LF tubular contém, em média, 0,015 g de mercúrio em seu interior (ZANICHELI et al., 2004); de acordo com a Portaria do Ministério da Saúde no 2.914/2011 (BRASIL, 2011), que define o valor máximo permitido (VMP) de mercúrio de $0,001 \mathrm{mg} \cdot \mathrm{L}^{-1}$ como o limite para que uma água seja considerada potável, tal quantidade de mercúrio tem potencial para tornar 15 mil L de água inviáveis para fins potáveis. Assim, considerando-se apenas as LFs inteiras descartadas, cerca de 2.169.000.000 L de água será poupado de contaminação, o equivalente, em volume, a 867 piscinas olímpicas, com a coleta e o descarte adequado deste resíduo tóxico.

Além disso, existe o risco de as lâmpadas se quebrarem. Segundo a Portaria MTb no 3.214, especificamente a Norma Regulamentadora 15 , que estabelece os limites de tolerância de trabalhadores a agentes químicos - para o mercúrio é de $0,04 \mathrm{mg} \cdot \mathrm{m}^{-3}$ de ar para $48 \mathrm{~h}$ de exposição semanal (BRASIL, 1978) —, uma exposição a esse valor corresponde a aproximadamente $15-20 \mu \mathrm{g}$ de Hg. $\mathrm{L}^{-1}$ de sangue, o que indica duplicação do nível de mercúrio no sangue em relação às concentrações observadas em populações não expostas $\left(1\right.$ a $\left.8 \mu \mathrm{g} . \mathrm{L}^{-1}\right)$ (REMPE; AMORIM; VASCONCELOS NETO, 2010). Assim, pode-se inferir, por meio de uma simulação, que a quebra de uma LF libera, em média, $15 \mathrm{mg}$ de $\mathrm{Hg}$ e que $1 / 3$ desse $\mathrm{Hg}$ se vaporiza imediatamente, ou seja, $5 \mathrm{mg}$ de $\mathrm{Hg}$, o que resultará em uma concentração de $0,1 \mathrm{mg} \cdot \mathrm{m}^{-3}$ em um ambiente com $45 \mathrm{~m}^{3}$ ( $25 \mathrm{~m}^{2}$ e 1,8 $\mathrm{m}$ de altura). Sabe-se, ainda, que essa concentração em um ambiente ventilado estará próxima de zero em cerca de 30 minutos, mas, de qualquer forma, é importante concluir que existe risco aos trabalhadores locais, sendo necessários o treinamento e o uso de equipamento de proteção individual (EPI).

Por sua vez, o orçamento para a retirada das lâmpadas é feito após a contagem e a definição dos tipos coletados, pois cada lâmpada tem um valor específico, sendo necessário realizar sua triagem e seleção. Não se teve acesso ao orçamento de 2014, sendo o custo da retirada das lâmpadas, em 2015, de R\$ 86.935 (Tabela 4).
Para a retirada das LFs no período de outubro de 2015 a julho de 2017, o orçamento foi de R 171.735 (Tabela 5).

\section{Estudo econômico da substituição das lâmpadas fluorescentes por lâmpadas light emitting diode (LED)}

No processo de seleção de um tipo de tecnologia nos sistemas de iluminação, um fator preponderante é o da eficiência energética, sendo decisivo na relação custo $\times$ benefício. Nesse contexto, optou-se por calcular os custos que relacionam as tecnologias de LF e de lâmpadas LED na UFU.

De acordo com os engenheiros da Divisão de Execução Física, a vida útil das LFs de $32 \mathrm{~W}$ utilizadas na instituição é de apenas três meses, ou 720 horas ( 12 h.dia $^{-1}, 5$ dias.semana ${ }^{-1}, 4$ semanas.mês ${ }^{-1}$ por 3 meses), enquanto para os fabricantes é de dois anos. Essa menor durabilidade das LFs justifica-se pela quantidade de acionamentos para acendimento por meio de interruptor fixo e de sensores de movimento existentes instalados em algumas salas, o que acelera o desgaste. De acordo com Qian, Lee e Yamauchi (1999), o desgaste do revestimento dos eletrodos depende do processo utilizado para ligar a lâmpada e do número de partidas a frio por horas de operação. A cada partida da LF sem preaquecimento dos filamentos, há redução média de 8 horas na sua vida útil, que costuma oscilar em torno de 7.500 horas.

Tabela 4 - Orçamento dos serviços de retirada de lâmpadas inteiras e quebradas de janeiro a setembro de 2015 na Universidade Federal de Uberlândia (UFU), Minas Gerais.

\begin{tabular}{l|c|c|c|c} 
& \multirow{2}{*}{ Tipo de serviço } & Quantidade & Unidade & \multicolumn{2}{|c}{ Valor de referência em R\$ } \\
\cline { 4 - 5 } $\begin{array}{l}\text { Retirada de } \\
\text { lâmpadas } \\
\text { inteiras }\end{array}$ & 38.000 & Peça & 2,12 & $80.560,00$ \\
\hline $\begin{array}{l}\text { Retirada de } \\
\text { lâmpadas } \\
\text { quebradas }\end{array}$ & 850 & $\mathrm{~kg}$ & 7,50 & $6.375,00$ \\
\hline \multicolumn{2}{l}{ Valor total } & & & $86.935,00$ \\
\hline
\end{tabular}

Fonte: com base em UFU (2017).

Tabela 5 - Orçamento dos serviços de retirada de lâmpadas inteiras e quebradas de outubro de 2015 a julho de 2017 na Universidade Federal de Uberlândia (UFU), Minas Gerais.

\begin{tabular}{l|c|c|c|c} 
& \multirow{2}{*}{ Tipo de serviço } & Quantidade & \multirow{2}{*}{ Unidade } & \multicolumn{2}{|c}{ Valor de referência em R\$ } \\
\cline { 4 - 5 } & & & Unitário & Total \\
\hline $\begin{array}{l}\text { Retirada de } \\
\text { lâmpadas } \\
\text { inteiras }\end{array}$ & 78.000 & Peça & 2,12 & $165.360,00$ \\
\hline $\begin{array}{l}\text { Retirada de } \\
\text { lâmpadas } \\
\text { quebradas }\end{array}$ & 850 & $\mathrm{~kg}$ & 7,50 & $6.375,00$ \\
\hline \multicolumn{2}{l}{\begin{tabular}{l} 
Valor total \\
\hline
\end{tabular}}
\end{tabular}

Fonte: com base em UFU (2017). 
Para duas LFs de $32 \mathrm{~W}$ é utilizado um reator que tem vida útil de 24 meses, sendo, portanto, necessárias 500 unidades para uma amostra de $1.000 \mathrm{LFs}$ de $32 \mathrm{~W}$.

Para as lâmpadas LED T8 $19 \mathrm{~W}$, equivalentes às fluorescentes de $32 \mathrm{~W}$, atualmente utilizadas na UFU, o tempo de vida útil estimado foi de 18 meses ou 4.320 horas ( 12 h.dia ${ }^{-1}, 5$ dias.semana $^{-1}, 4$ semanas. mês ${ }^{-1}$ por 18 meses), bem inferior ao que é informado pelos fabricantes (40 mil horas). Essa menor quantidade de horas foi determinada em termos experimentais pelos técnicos da instituição, que alegam menor durabilidade das lâmpadas em decorrência das licitações que priorizam o menor preço, e não a qualidade. Além disso, é comum lâmpadas LED não atenderem ao nível de luminosidade que um ambiente escolar exige, sendo necessária a sua substituição antes de queimar.

Para o Instituto Nacional de Metrologia, Normalização e Qualidade Industrial (INMETRO, 2017), as lâmpadas LED mantêm sua luminosidade a um bom nível até 25 mil h de uso. Alguns fatores não relacionados com a qualidade do produto também podem afetar a sua durabilidade, como oscilações da rede elétrica ou o mau contato no ponto de instalação.

Assim, a partir dessas informações, foram avaliados dois cenários para a substituição das LFs, o primeiro considerando a vida útil das lâmpadas LED de 4.320 horas de acordo com técnicos da UFU e o segundo de $40 \mathrm{mil} \mathrm{h}$, segundo os fabricantes.

Para determinar o custo da substituição das LFs para os dois cenários, os valores de aquisição das LFs + reatores e das LED, bem como os preços para a retirada das LFs, foram extraídos dos pregões eletrônicos realizados em 2017 na UFU, disponíveis no site Comprasnet, do governo federal, e o valor da mão de obra foi fornecido pela Divisão de Execução Física. Nos dois cenários, foi considerado um período de 8 meses, o que corresponde ao calendário acadêmico anual da UFU, ou seja, 2 semestres de 4 meses letivos em sala de aula e 4 meses com utilização irrelevante ao estudo, já que nesse período a instituição se dedica à manutenção da rede elétrica e afins.

No primeiro cenário, para a reposição das 1.000 LFs, serão necessárias 2.667 lâmpadas anualmente ( 1 mil unidades $\times 12$ h.dia $^{-1} \times 5$ dias. semana $^{-1} \times 4$ semanas.mês ${ }^{-1} \times 8$ meses e dividido por 720 h) e 500 reatores com vida útil de 24 meses, segundo os fabricantes. Assim, para 1.000 LFs e tendo os reatores uma durabilidade estimada de 5.760 horas (12 h.dia $^{-1} \times 5$ dias.semana ${ }^{-1} \times 4$ semanas.mês ${ }^{-1} \times 24$ meses), serão necessários 167 reatores $\left(500\right.$ unidades $\times 12$ h.dia $^{-1} \times 5$ dias.semana ${ }^{-1} \times 4$ semanas.mês ${ }^{-1} \times 8$ meses e dividido por 5.760 horas) (Tabela 6). Quanto às lâmpadas LED, para essa amostra de mil unidades, serão necessárias 444 (1.000 unidades $\times 12$ h.dia $^{-1} \times 5$ dias.semana ${ }^{-1} \times 4$ semanas. mês ${ }^{-1} \times 8$ meses e dividido por 4.320 horas).

Para o cálculo do valor da mão de obra em horas pagas aos eletricistas e ajudantes que executarão as substituições de LF pelas lâmpadas LED na UFU, considerou-se o custo mensal de cada profissional. O tempo utilizado na troca de uma lâmpada é de 15 minutos, que corresponde ao valor total de R 12,75 (Tabela 7). Para se chegar a esse valor do homem.h-1 em reais para os profissionais, dividiu-se o custo de cada profissional $(\mathrm{R} \$ 6.311,04$ e $\mathrm{R} \$ 4.913,15)$ por 220 horas (que equivale a 44 h.semana ${ }^{-1} \times 5$ semanas, conforme Consolidação das Leis do Trabalho - CLT; BRASIL, 1943). Em seguida, calcularam-se os valores dos custos para substituição de cada lâmpada (dividindo-se os valores de $\mathrm{R} \$ 28,69$ e R $\$ 22,33$ por 60 minutos e multiplicando-os por 15 minutos). Somaram-se os dois valores e obteve-se o custo total por troca de lâmpada.

Para que essas lâmpadas sejam recolhidas, as empresas contratadas cobram valores diferenciados para a retirada das inteiras e quebradas. Nesse universo de 2.667 lâmpadas retiradas, $99 \%$ delas foram consideradas como inteiras (2.640 unidades) e o restante, como quebradas (27 unidades).

Assim, o valor gasto em um ano, considerando todos os custos com as LFs é de $\mathrm{R} \$ 55.373,36$. Em contrapartida, nesse período não será necessário efetuar gastos com a manutenção das lâmpadas LED, somente uma provisão orçamentária no valor de R 23.421 incluindo mão de obra. Comparando-se esses valores, significa que haveria uma economia de R \$ 31.952,36 no orçamento anual da instituição (Tabela 8).

O segundo cenário considerou a vida útil para as LFs as mesmas 720 horas e para as lâmpadas LED um total de 13 anos, o que equivale a aproximadamente 40 mil horas de vida útil, informada pelos fabricantes de lâmpadas (Tabela 9).

A análise do segundo cenário demonstra os valores gastos na compra das lâmpadas, dos reatores e da mão de obra para a retirada gradativa das LFs ao longo de 13 anos. A manutenção e a mão de obra permanecem as mesmas para as LFs. Nesse período, não há gastos com a manutenção das lâmpadas LED, somente provisão orçamentária no valor de R\$ 2.532 incluindo mão de obra. Comparando esses valores,

\begin{tabular}{|c|c|c|c|}
\hline Tipo de lâmpada & Quantidade & $\begin{array}{c}\text { Tempo } \\
\text { de vida (h) }\end{array}$ & $\begin{array}{c}\text { Quantidade necessária } \\
\text { no ano letivo }\end{array}$ \\
\hline $\begin{array}{l}\text { Lâmpadas } \\
\text { fluorescentes }\end{array}$ & 1.000 & 720 & 2.667 \\
\hline Reator & 500 & 5.760 & 167 \\
\hline $\begin{array}{l}\text { Lâmpada LED } \\
\text { tubular T8 } 19 \text { W }\end{array}$ & 1.000 & 4.320 & 444 \\
\hline
\end{tabular}

LED: light emitting diode.

Tabela 7 - Custos com mão de obra para substituição de lâmpada fluorescente por lâmpadas light emitting diode (LED) na Universidade Federal de Uberlândia (UFU), Minas Gerais.

\begin{tabular}{l|c|c|c} 
Mão de obra & $\begin{array}{c}\text { Custo de mão de obra } \\
\text { total para a UFU (R\$) }\end{array}$ & $\begin{array}{c}\text { Homem. } \\
\text { hora }^{-1} \text { (R) }\end{array}$ & $\begin{array}{c}\text { Custo por } \\
\text { lâmpada (R\$) }\end{array}$ \\
\hline Eletricista & $6.311,04$ & 28,69 & 7,17 \\
\hline Ajudante & $4.913,15$ & 22,33 & 5,58 \\
\hline Total & $11.224,19$ & 51,02 & 12,75 \\
\hline
\end{tabular}


significa que haveria uma economia de $\mathrm{R} \$ 52.841,36$ no orçamento anual da Instituição (Tabela 10).

O custo do kWh médio pago pela UFU à concessionária de energia elétrica de Minas Gerais informado pela Diretoria de Sustentabilidade é de $\mathrm{R} \$ 0,37$. Obteve-se o valor da energia elétrica multiplicando-se 12 h.dia $^{-1} \times 5$ dias.semana ${ }^{-1} \times 4$ semanas.mês ${ }^{-1} \times 8$ meses pela potência em watts de $39.500 \mathrm{~W}[(1.000 \mathrm{LFs} \times 32 \mathrm{~W})+(500$ reatores $\times 15 \mathrm{~W})]$

Tabela 8 - Gasto anual das lâmpadas fluorescentes (LF) e lâmpadas light emitting diode (LED) em R\$ na Universidade Federal de Uberlândia (UFU), Minas Gerais (Cenário 1).

\begin{tabular}{l|c|c|c} 
Tipo de lâmpada & $\begin{array}{c}\text { Unitário } \\
(\mathrm{R} \$)\end{array}$ & $\begin{array}{c}\text { Gasto anual } \\
\text { quantidade }\end{array}$ & $\begin{array}{c}\text { Valor total } \\
\text { anual (R\$) }\end{array}$ \\
\hline Lâmpada fluorescente 32 W & 4,93 & 2.667 & $13.148,31$ \\
\hline Retirada de lâmpadas inteiras & 2,12 & 2.640 & $5.596,80$ \\
\hline Retirada de lâmpadas quebradas & 7,50 & 27 & 202,50 \\
\hline Reator & 14,50 & 167 & $2.421,50$ \\
\hline Mão de obra & 12,75 & 2.667 & $34.004,25$ \\
\hline Custo total de LF (I) & 40,00 & 444 & $17.760,00$ \\
\hline Lâmpada LED tubular T8 19 W & 12,75 & 444 & $5.661,00$ \\
\hline Mão de obra & & $23.421,00$ \\
\hline Custo total LED (II) & & $31.952,36$ \\
\hline Diferença de custo LF/LED (I - II)
\end{tabular}

Tabela 9 - Quantidade de lâmpadas previstas por ano na Universidade Federal de Uberlândia, Minas Gerais (Cenário 2).

\begin{tabular}{l|c|c|c} 
Tipo de lâmpada & Quantidade & $\begin{array}{c}\text { Tempo de } \\
\text { vida (h) }\end{array}$ & $\begin{array}{c}\text { Quantidade para } \\
\text { a substituição de } \\
\text { acordo com a vida útil }\end{array}$ \\
$\begin{array}{l}\text { Lâmpada } \\
\text { fluorescente }\end{array}$ & 1.000 & 720 & 2.667 \\
\hline Reator & 500 & 5.760 & 167 \\
\hline $\begin{array}{l}\text { Lâmpada LED } \\
\text { tubular T8 19 W }\end{array}$ & 1.000 & 40.000 & 48 \\
\hline
\end{tabular}

LED: light emitting diode.

Tabela 10 - Gastos das lâmpadas fluorescentes (LF) e lâmpadas light emitting diode (LED) em R \$ na Universidade Federal de Uberlândia, Minas Gerais (Cenário 2).

\begin{tabular}{l|c|c|c} 
Tipo de lâmpada & $\begin{array}{c}\text { Unitário } \\
(\mathrm{R} \$)\end{array}$ & $\begin{array}{c}\text { Gasto anual } \\
\text { quantidade }\end{array}$ & $\begin{array}{c}\text { Valor total } \\
\text { anual (R\$) }\end{array}$ \\
\hline Lâmpada fluorescente 32 W & 4,93 & 2.667 & $13.148,31$ \\
\hline Retirada de lâmpadas inteiras & 2,12 & 2.640 & $5.596,80$ \\
\hline Retirada de lâmpadas quebradas & 7,50 & 27 & 202,50 \\
\hline Reator & 14,50 & 167 & $2.421,50$ \\
\hline Mão de obra & 12,75 & 2.667 & $34.004,25$ \\
\hline Custo total de LF & 40,00 & 48 & $1.920,00$ \\
\hline Lâmpada LED tubular T8 19 W & 12,75 & 48 & 612,00 \\
\hline Mão de obra & & $2.532,00$ \\
\hline Custo total LED & & $52.841,36$ \\
\hline Diferença de custo LF/LED
\end{tabular}

para as LFs e de 1.920 multiplicado por $19.000 \mathrm{~W}(1.000 \mathrm{LED} \times 19 \mathrm{~W})$ para as lâmpadas LED, dividido pela quantidade da amostra (1.000 LFs), multiplicado pelo custo do $\mathrm{kWh}(\mathrm{R} \$ 0,37)$. Assim, o custo anual gerado com LF foi de R $\$ 28.060,80$, enquanto o custo das lâmpadas LED foi de R\$ 13.497,60, proporcionando uma economia anual considerável de R\$14.563,20 em ambos os cenários, haja vista que o tempo de duração das lâmpadas não influi no consumo (Tabela 11).

$\mathrm{O}$ valor da tarifa considerada nos cálculos do kW.h-1 pagos pela universidade à empresa fornecedora de energia elétrica é a média entre o consumo dentro e fora do horário de ponta. Horário de ponta é aquele em que há o consumo muito alto de energia no sistema de fornecimento e, consequentemente, o valor do $\mathrm{kW} . \mathrm{h}^{-1}$ é mais caro, sendo o horário fora de ponta aquele em que o consumo de energia é menor e o preço também.

Os valores dos custos da mão de obra do eletricista e do ajudante para os dois cenários são os mesmos. Assim, a economia total anual com a compra de lâmpadas, a mão de obra especializada e a energia elétrica, considerando a estimativa de vida útil de 18 meses para as lâmpadas LED, é de R \$ 46.515,56 e para 167 meses, de R 67.404,56, ou seja, entre 55,75 e 80,78\% no fim de 13 anos (Tabela 12).

Outra análise importante deste estudo é o comparativo entre o custo total de R \$ 55.373,36 das LFs para a amostra de mil lâmpadas e o custo total das lâmpadas LED de R \$ 52.750 [custo da lâmpada + custo da mão de obra $(\mathrm{R} \$ 52,75) \times 1.000$ unidades] para o mesmo período, o que proporcionaria um retorno do montante gasto já ao final do primeiro ano.

Tendo em vista que a amostra foi de mil lâmpadas para apenas um bloco, é possível afirmar que, caso a substituição se estenda por todas

Tabela 11 - Economia energética da substituição de lâmpada fluorescente (LF) por light emitting diode (LED) na Universidade Federal de Uberlândia, Minas Gerais, em ambos os cenários.

\begin{tabular}{l|c|c|c|c} 
& $\begin{array}{c}\text { Gasto } \\
\text { anual (h) }\end{array}$ & $\begin{array}{c}\text { Potência } \\
(\mathrm{W})\end{array}$ & $\begin{array}{c}\text { Preço médio } \\
\left(\mathrm{kW} \cdot \mathrm{h}^{-1}\right)\end{array}$ & Total (R\$) \\
$\begin{array}{l}\text { Fluorescentes } \\
32 \mathrm{~W}+\text { reator (I)) }\end{array}$ & 1.920 & 39.500 & 0,37 & $28.060,80$ \\
\hline LED tubular T8 19 W (II) & 1.920 & 19.000 & 0,37 & $13.497,60$ \\
\hline \multicolumn{7}{|l}{ Economia anual (I - II) } & $14.563,20$ \\
\hline
\end{tabular}

Tabela 12 - Economia anual com a substituição das lâmpadas fluorescentes pelas lâmpadas light emitting diode (LED) na Universidade Federal de Uberlândia, Minas Gerais.

\begin{tabular}{l|c|c|c|c}
$\begin{array}{l}\text { Quantidade } \\
\text { em meses }\end{array}$ & $\begin{array}{c}\text { Diferença } \\
\text { Custo de } \\
\text { lâmpadas (R\$) }\end{array}$ & $\begin{array}{c}\text { Diferença } \\
\text { mão de } \\
\text { obra (R\$) }\end{array}$ & $\begin{array}{c}\text { Diferença } \\
\text { de gasto } \\
\text { de energia } \\
\text { elétrica (R\$) }\end{array}$ & $\begin{array}{c}\text { Economia } \\
\text { total (custo + } \\
\text { mão de obra } \\
\text { +energia } \\
\text { elétrica) (R\$) }\end{array}$ \\
\hline 18 & $3.609,11$ & $28.343,25$ & $14.563,20$ & $46.515,56$ \\
\hline 167 & $19.449,11$ & $33.392,25$ & $14.563,20$ & $67.404,56$ \\
\hline
\end{tabular}


as salas de aulas e demais dependências da UFU, a economia com a compra de lâmpadas, seu recolhimento, a mão de obra e o gasto com energia elétrica seria considerável, o que permitiria a realocação de recursos financeiros para atender a outras demandas da instituição.

\section{CONCLUSÃO}

As lâmpadas LED sobressaem nos aspectos de manutenibilidade, durabilidade, eficiência energética, economia e menores impactos ambientais, podendo ser até duas vezes mais eficientes que as LFs, além de não gerarem resíduos tóxicos.

Diante desse cenário, constata-se a viabilidade econômico-financeira para a substituição das LFs por lâmpadas LED na UFU, pois, considerando-se uma amostra de mil LFs, projetam-se uma economia entre 55,75 e $80,78 \%$ ao completar 13 anos e um retorno do montante gasto ao final do primeiro ano. Não obstante, o que mais se destaca nessa experiência é a importância da substituição do ponto de vista ambiental, por contemplar ações de sustentabilidade, principalmente, em uma instituição de ensino.

\section{REFERÊNCIAS}

ABDALLA, S. (2017) Agora é definitivo: você não pode mais comprar lâmpadas incandescentes. Gazeta do Povo. Disponível em: <http://www. gazetadopovo.com.br/haus/imoveis/agora-e-definitivo-voce-nao-podemais-comprar-lampadas-incandescentes/>. Acesso em: 17 jul. 2017.

AGUILAR, R.C.S. (2015) Destino de lâmpadas fluorescentes pósconsumo: estudo de caso em um estabelecimento de Governador Valadares - MG. Instituto Federal de Educação, Ciências e Tecnologia de Minas Gerais - IFMG, Governador Valadares. 16 p. Disponível em: $<$ http://www3.ifmg.edu.br/site_campi/v/images/arquivos_governador_ valadares/TCC Rinara.pdf>. Acesso em: 9 abr. 2017.

ASSOCIAÇÃO BRASILEIRA DE NORMAS TÉCNICAS (ABNT). (2004) ABNT NBR 10004: resíduos sólidos: classificação. 2. ed. Rio de Janeiro: ABNT. 71 p. Disponível em: <www.abnt.org.br>. Acesso em: 18 ago. 2017

BACILA, D.M. (2012) Uso da logística reversa para apoiar a reciclagem de lâmpadas fluorescentes usadas: estudo comparativo entre Brasil e Alemanha. 152 f. Dissertação (Mestrado em Meio Ambiente) - Universidade Federal do Paraná, Curitiba. Disponível em: <http://acervodigital.ufpr.br/bitstream/handle/1884/28134/R\%20 -\%20D\%20-\%20DANNIELE\%2OMIRANDA\%2OBACILA. pdf?sequence=1\&isAllowed=y>. Acesso em: 3 jan. 2017.

BLEY, F.B. (2012) LEDs versus lâmpadas convencionais: viabilizando a troca. Revista Especialize Online. Disponível em: <https://www. google.com.br/search?q=BLEY,+F.+B.+LEDs+versus+1\%C3\%A2mpa das+convencionais+viabilizando+a+troca.+IPOG:+Revista+on+line+ Especialize.+2012.+\&ie=utf-8\&oe=utf-8\&client=firefox-b\&gws_rd=cr $\& d c r=0 \& e i=G W 7 j W d p F g v 7 A B P L 6 u o g C>$. Acesso em: 10 fev. 2017.

BRASIL. (1943) Decreto-Lei no 5.452, de 10 de maio de 1943. Aprova a Consolidação das Leis do Trabalho. Diário Oficial da União, Brasília. Disponível em: <http://www.planalto.gov.br/ccivil_O3/decreto-lei/ Del5452compilado.htm>. Acesso em: 21 jul. 2019.

BRASIL. (1978) Ministério do Trabalho e Emprego. Portaria MTb no 3.214, de 8 de junho de 1978. Norma Regulamentadora NR-15 - Atividades e operações insalubres. Diário Oficial da União, Brasília. Disponível em: <http://www.ccb.usp.br/arquivos/ arqpessoal/1360237303_nr15atualizada2011ii.pdf>. Acesso em: 12 ago. 2017.

BRASIL. (2001) Lei n010.295, de17 de outubro de 2001. Lei de Eficiência Energética. Dispõe sobre a Política Nacional de Conservação e uso racional de energia e dá outras providências. Diário Oficial da União, Brasilia. Disponível em: <http://www.planalto.gov.br/ccivil_03/leis/ LEIS_2001/L10295.htm>. Acesso em: 24 abr. 2017.

BRASIL. (2010) Lei no 12.305, de 2 de agosto de 2010. Política Nacional de Resíduos Sólidos. Institui a Política Nacional de Resíduos Sólidos; altera a Lei no 9.605, de 12 de fevereiro de 1998; e dá outras providências. Diário Oficial da União, Brasília. Disponível em: <http:// www.planalto.gov.br/ccivil_03/_ato2007-2010/2010/lei/112305.htm> Acesso em: 21 fev. 2017

BRASIL. (2011) Portaria do Ministério da Saúde no 2.914, de 12 de dezembro de 2011. Dispõe sobre os procedimentos de controle e de vigilância da qualidade da água para consumo humano e seu padrão de potabilidade. Brasília: Ministério da Saúde. Disponível em: <http:// bvsms.saude.gov.br/bvs/saudelegis/gm/2011/prt2914_12_12_2011. html> Acesso em: 12 ago. 2017.

CESTARI, W.; MARTINS, C.H. (2015) Logística reversa de lâmpadas fluorescentes pós-consumo: estudo de caso: sistema de armazenagem em uma instituição de ensino. Revista Eletrônica em Gestão, Educação e Tecnologia Ambiental, Santa Maria, v. 19, n. 3. p. 124-135. http://dx.doi.org/10.5902/2236117017725

COMINI, U.B.; AZEVEDO, M.A.; MOSTARO, G.V.; ZAMPERLINI, B. (2016) Propostas para melhoria do sistema de gerenciamento de lâmpadas de descarga pós-consumo em instituição de ensino superior. Universidade Federal de Viçosa, Viçosa. 9 p. Disponível em: <http://www.residuos.ufv.br/wp-content/uploads/38-T8-CominiBrasil.pdf>. Acesso em: 18 fev. 2017.

CONSELHO REGIONAL DE QUÍMICA - IV REGIÃO. (2015) Comissão de Meio Ambiente. Aspectos jurídicos e tecnológicos da política de resíduos sólidos. São Paulo: CRQ IV. 51 p. Disponível em: <http:// www.crq4.org.br/sms/files/file/ctma_asp_jur_tec_pnrs_2015_final pdf>. Acesso em: 15 abr. 2017. 
CREPALDI, J.A.; FRIGATTI, M.F.; LUCKOW, R. (2012) Análise da vida útil de lâmpadas fluorescentes utilizando diferentes tipos de circuitos de pré-aquecimento. 91 f. Trabalho de Conclusão de Curso (Graduação em Engenharia Industrial Elétrica) Universidade Tecnológica Federal do Paraná, Curitiba. Disponível em: <http://repositorio.roca.utfpr.edu.br/jspui/bitstream/1/680/1/ CT_COELE_2012_1_04.pdf>. Acesso em: 14 mar. 2017.

DEGRA, A.; GOBI, E. (2015) Logística reversa. Lume Arquitetura, v. 73, p. 20-25. Disponível em: <http://lumearquitetura.com.br/pdf/ ed73/ed_73\%2OEs\%20-\%2OLog\%C3\%ADstica\%2Oreversa.pdf>. Acesso em: 18 fev. 2017.

ESTRELA, M.A.A.; ROHLFS, D.B. (2014) Mercúrio: implicações para saúde e meio ambiente. Pontifícia Universidade Católica de Goiás, Goiânia. 18 p. Disponível em: <http://www.cpgls. pucgoias.edu.br/7mostra/Artigos/SAUDE\%2OE\%2OBIOLOGICAS/ MERCURIO\%2O-\%2OIMPLICA\%C3\%87\%C3\%95ES\%2OPARA\%2O A\%2OSA\%C3\%9ADE\%2OE\%200\%2OMEIO\%2OAMBIENTE.pdf>. Acesso em: 12 jul. 2017.

GUSMÃO, S. (2017) Brasil inicia processo para instalação da logística reversa. Ministério do Meio Ambiente. Disponível em: <http:// www.mma.gov.br/informma/item/7015-brasil-inicia-processo-parainstalacao-da-logistica-reversa>. Acesso em: 27 jul. 2017.

INSTITUTO NACIONAL DE METROLOGIA, QUALIDADE E TECNOLOGIA (INMETRO). (2017) Seis coisas sobre a norma do INMETRO para lâmpadas LED que você deve saber. Inmetro. Disponível em: <http://www.portaldoled.com.br/6-coisas-sobrea-norma-do-inmetro-para-lampadas-led-que-voce-deve-saber>. Acesso em: 17 jul. 2017.

LIMA, V.A.A. (2013) Estudo comparativo entre lâmpadas com LED de alta potência e lâmpadas comuns considerando a viabilidade econômica. 74 f. Trabalho de Conclusão de Curso (Graduação em Eletrotécnica) - Universidade Tecnológica Federal do Paraná, Curitiba. Disponível em: <http://repositorio.roca.utfpredu.br/jspui/ bitstream/1/2067/1/CT_COALT_2013_1_02.pdf>. Acesso em: O2 fev. 2017.

LIMA, V.D. (2007) Procuradoria Geral da República. Secretaria de Administração do MPF. Programa de Gestão Ambiental. Projeto de Descontaminação de Lâmpadas com Mercúrio. Brasília: PGR/ MPF. 15 p. Disponível em: <http://cpsustentaveis.planejamento. gov.br/assets/conteudo/uploads/projeto-de-descontaminacao-delampadas-com-mercurio.pdf>. Acesso em: 2 fev. 2017.

MAIA, H.J.L.; ALENCAR, L.D.; BARBOSA, E.M.; BARBOSA, M.F.N. (2014) Política nacional de resíduos sólidos: um marco na legislação ambiental brasileira. Revista Polêmica, v. 13, n. 1. Disponível em: $<$ https://www.e-publicacoes.uerj.br/index.php/polemica/article/ view/9636/7561>. Acesso em: 23 mar. 2017.

NAIME, R.; GARCIA, A.C. (2004) Propostas para o gerenciamento de resíduos de lâmpadas fluorescentes. Espaço para a Saúde, Londrina, v. 6, n. 1, p. 1-6.
QIAN, J.; LEE, F.C.; YAMAUCHI, T. (1999) Charge pump power-factorcorrection dimming electronic ballast. IEEE Transactions on Power Electronics, v. 14, n. 3, p. 461-468. https://doi.org/10.1109/63.761690

RECICLUS. (2017) Programa: homepage. Disponível em: <http:// www.reciclus.org.br/index.php?content=8>. Acesso em: 5 jun. 2017.

REMPE, E.F;; AMORIM, L.A.; VASCONCELOS NETO, R. (Coords.). (2010) Coletânea de informações sobre o mercúrio incluindo padrões ambientais no Brasil. In: REUNIÃO DO GRUPO DE TRABALHO LÂMPADAS MERCURIAIS DA CSSAGR DO CONAMA, 4., 2010, Brasília. Atas... Brasília: Ministério da Saúde. 13 p. Disponível em: <http://www.mma.gov.br/port/conama/processos/OE732C8D/ ColetaneaHg_MinSaude_27jan1O.pdf>. Acesso em: 5 jun. 2017.

SANCHES, E.S.S. (2008) Logística reversa de pós-consumo do setor de lâmpadas fluorescentes. In: CONGRESSO NACIONAL DE ENGENHARIA MECÂNICA, 5., 2008. Anais... Salvador, p. 18-22.

SANTOS, T.S.; BATISTA, M.C.; POZZA, S.A.; ROSSI, L.S. (2015) Análise da eficiência energética, ambiental e econômica entre lâmpadas de LED e convencionais. Revista Engenharia Sanitária e Ambiental, v. 20, n. 4, p. 595-602. http://doi.org/101590/S141341522015020040125106

SHIBÃO, F.Y; MOORI, R.G.; SANTOS, M.R. (2010) A logística reversa e a sustentabilidade empresarial. In: SEMEAD - SEMINARIOS EM ADMINISTRAÇÃO, 13., 2010. Anais... 17 p. Disponível em: <http:// web-resol.org/textos/a_logistica_reversa_e_a_sustentabilidade empresarial.pdf>. Acesso em: 20 set. 2017.

UNIVERSIDADE FEDERAL DE UBERLÂNDIA (UFU). (2014) Prefeitura Universitária. Diretoria de Sustentabilidade. Projeto básico. Projeto referente à contratação de serviços de coleta de lâmpada. Uberlândia.

UNIVERSIDADE FEDERAL DE UBERLÂNDIA (UFU). (2015) Prefeitura Universitária. Diretoria de Sustentabilidade. Projeto básico. Projeto referente à contratação de serviços de coleta de lâmpada. Uberlândia.

UNIVERSIDADE FEDERAL DE UBERLÂNDIA (UFU). (2017) A universidade. Uberlândia: UFU. Disponível em: <www.ufu.br>. Acesso em: 20 set. 2017.

USP PREFEITURA: CAMPUS DA CAPITAL. (2017) Meta de sustentabilidade: Lâmpadas fluorescentes. USP Prefeitura: Campus da Capital, São Paulo. Disponível em: <http://www.puspc.usp.br/ extrato-de-sustentabilidade-lampadas/>. Acesso em: 30 set. 2017.

ZANICHELI, C.; PERUCHI, I.B.; MONTEIRO, L.A.; JOÃO, S.A.S.; CUNHA, V.F. (2004) Reciclagem de lâmpadas: aspectos ambientais e tecnológicos. Pontifícia Universidade Católica de Campinas, Campinas. 22 p. Disponível em: <http://www.iar.unicamp.br/ lab/luz/ld/L\%E2mpadas/reciclagem_de_lampadas_aspectos_ ambientais_e_tecnologicos.pdf>. Acesso em: 30 set. 2017. 